\title{
Commentary: Transaortic transcatheter aortic valve implantation: A route to be protected and not neglected
}

Francesco Formica, MD, ${ }^{\mathrm{a}}$ Gurmeet Singh, MD, FRCSC, ${ }^{\mathrm{b}}$ and Stefano D’Alessandro, MD, FECTS ${ }^{\mathrm{a}}$

From the ${ }^{\mathrm{a} C a r d i a c}$ Surgery Unit, San Gerardo Hospital, and Department of Medicine and Surgery, University of Milano-Bicocca, Monza, Italy; and ${ }^{b}$ Department of Critical Care Medicine and Surgery, Division of Cardiac Surgery, Mazankowski Alberta Heart Institute, University of Alberta, Edmonton, Alberta, Canada.

Disclosures: Authors have nothing to disclose with regard to commercial support.

Received for publication July 29, 2018; accepted for publication July 30, 2018; available ahead of print Sept 6, 2018.

Address for reprints: Francesco Formica, MD, Clinica Cardiochirurgica, Ospedale San Gerardo, ASST Monza,

Via G.B. Pergolesi 33, 20052, Monza (MB), Italy (E-mail: francesco_formica@ fastwebnet.it).

J Thorac Cardiovasc Surg 2019;157:1404-5

$0022-5223 / \$ 36.00$

Copyright (c) 2018 by The American Association for Thoracic Surgery

https://doi.org/10.1016/j.jtcvs.2018.07.089

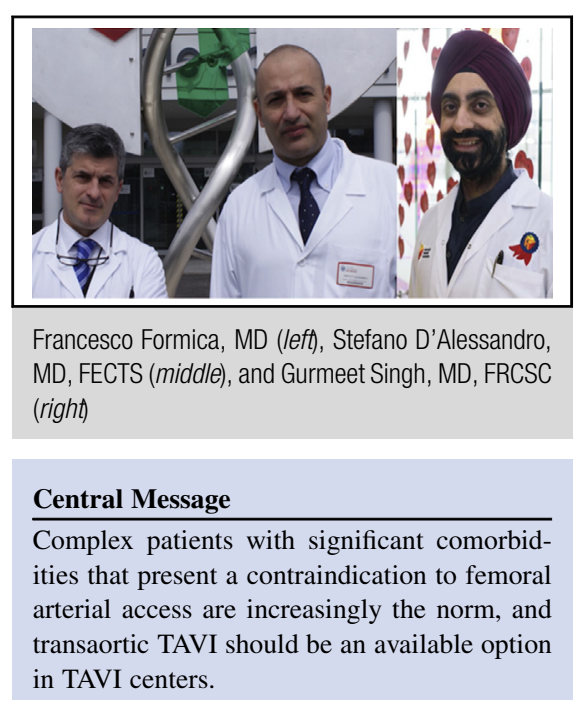

See Article page 1393.
Transcatheter aortic valve implantation (TAVI) is an accepted technique in a heart team's armamentarium for management of intermediate- and high-risk patients with severe aortic stenosis. ${ }^{1}$ The transapical approach, the initial technique described for TAVI, has declined in use compared with the transfermoral (TF) approach and newer, alternative routes. This may be attributed to the emergence of downsized delivery systems and to the more relevant role of the alternative routes (eg, axillary artery, carotid artery, and direct aortic approaches), 2,3 during the past decade.

Porterie and colleagues ${ }^{4}$ share their very encouraging experience with transaortic TAVI (TAo-TAVI). The authors reported early and 1-year data on 206 high-risk patients between January 2012 and December 2016. During the same period, 796 patients underwent TF-TAVI. In addition to low 30 -day and 1-year overall mortality $(5.3 \%$ and $15.5 \%$, respectively), they report a low incidence of mild and moderate paravalvular leakage at 30 days $(6 \%$ and $0 \%$, respectively) and at 1-year follow-up $(6.5 \%$ and $1.6 \%$, respectively), low rates of cerebrovascular events $(1.5 \%$ and $3.9 \%$, at 30 days and 1 year, respectively), acceptable incidence $(10.2 \%)$ of perioperative acute kidney injury (AKI), and an acceptable rate of postoperative permanent pacemaker requirement $(9.7 \%)$.

Reducing complications associated with minimally invasive procedures is critical. We agree with the authors that exacting precision in valve positioning via the TA route may reduce the rates of most of the common complications described in TF-TAVI. Such complications are independent predictors of early and midterm mortality. ${ }^{5-8}$

An important point is the relatively low incidence of perioperative AKI reported in this study. In high-risk populations, perioperative AKI remains a significant concern. Notably, TAo-TAVI generally requires less contrast administration than the TF route because endovascular catheter manipulation of the descending aorta and arch is unnecessary. As the authors correctly state, this is of paramount importance also in reducing the risk of cerebrovascular events and major vascular complications. Furthermore, TAo-TAVI permits direct visualization of the aorta, with the ability to select a safe aortic cannulation site, mainly in extremely calcified aorta.

Determining the patient population that most benefits from TAo-TAVI remains challenging. It is difficult to compare TF-TAVI with TAo-TAVI because the latter group is ineligible for femoral access. It is possible that such a study might favor the TAo-TAVI technique even in TF patients, ${ }^{3}$ as recently reported. ${ }^{9}$ Alternatively, TAo-TAVI patients who are ineligible for TF-TAVI can be evaluated against the outcomes of surgical aortic valve replacement.

TAo-TAVI merits important consideration in the spectrum of TAVI procedures. Despite the encouraging results, this technique has important limitations that should be highlighted. Firstly, it is a surgical operation requiring general anesthesia. Secondly, it should be performed in centers with a hybrid operating room. Finally, it may require a relatively long learning curve for heart teams. ${ }^{10}$ Progressively complex patients with significant comorbidities that present absolute contraindication to TF access are increasingly the norm, and TAo-TAVI should be an available option in centers performing TAVI procedures. A route that deserves to be protected and not neglected. 


\section{References}

1. Baumgartner H, Falk V, Bax JJ, De Bonis M, Hamm C, Holm PJ, et al. 2017 ESC/ EACTS guidelines for the management of valvular heart disease. Eur Heart $J$. 2017;38:2739-91.

2. Hayashida K, Romano M, Lefèvre T, Chevalier B, Farge A, Hovasse T, et al. The transaortic approach for transcatheter aortic valve implantation: a valid alternative to the transapical access in patients with no peripheral vascular option. A single center experience. Eur J Cardiothorac Surg. 2013;44:692-700.

3. McCarthy FH, Spragan DD, Savino D, Dibble T, Hoedt AC, McDermott KM, et al. Outcomes, readmissions, and costs in transfemoral and alterative access transcatheter aortic valve replacement in the US Medicare population. J Thorac Cardiovasc Surg. 2017;154:1224-32.

4. Porterie J, Mayeur N, Lhermusier T, Dumonteil N, Chollet T, Lairez O, et al. Aortic and innominate routes for transcatheter aortic valve implantation. $J$ Thorac Cardiovasc Surg. 2019;157:1393-401.e7.

5. Azarbal A, Leadholm KL, Ashikaga T, Solomon RJ, Dauerman HL. Frequency and prognostic significance of acute kidney recovery in patients who underwent transcatheter aortic valve implantation. Am J Cardiol. 2018;121:634-41.

6. Gargiulo G, Sannino A, Capodanno D, Perrino C, Capranzano P, Barbanti M, et al. Impact of postoperative acute kidney injury on clinical outcomes after trans-

catheter aortic valve implantation: a meta-analysis of 5,971 patients. Catheter Cardiovasc Interv. 2015;86:518-27.

7. Salizzoni S, D’Onofrio A, Agrifoglio M, Colombo A, Chieffo A, Cioni M, et al. Early and mid-term outcomes of 1904 patients undergoing transcatheter balloonexpandable valve implantation in Italy: results from the Italian transcatheter balloon-expandable valve implantation registry (ITER). Eur J Cardiothorac Surg. 2016;50:1139-48.

8. Takagi H, Umemoto T, ALICE (All-Literature Investigation of Cardiovascular Evidence) Group. Impact of paravalvular aortic regurgitation after transcatheter aortic valve implantation on survival. Int J Cardiol. 2016; 221:46-51.

9. Chollet T, Marcheix B, Boudou N, Elbaz M, Campelo-Parada F, Bataille V, et al. Propensity matched comparison of clinical outcomes after transaortic versus transfemoral aortic valve replacement. Eurointervention. July 3, 2018 [Epub ahead of print].

10. Bavaria JE, Tommaso CL, Brindis RG, Carroll JD, Deeb GM, Feldman TE, et al. 2018 AATS/ACC/SCAI/STS expert consensus systems of care document: operator and institutional recommendations and requirements for transcatheter aortic valve replacement. J Thorac Cardiovasc Surg. 2019 73:340-74. 